\title{
Repeated influenza vaccination for preventing severe and fatal influenza infection in older adults: a multicentre case-control study
}

\author{
Itziar Casado MD, Ángela Domínguez MD PhD, Diana Toledo MPH, Judith Chamorro MD, Jenaro Astray MD PhD, \\ Mikel Egurrola MD, María Amelia Fernández-Sierra MD, Vicente Martín PhD, María Morales-Suárez-Varela PhD, \\ Pere Godoy MD PhD, Jesús Castilla MD PhD; for the Project PI12/02079 Working Group
}

- Cite as: CMAJ 2018 January 8;190:E3-12. doi: 10.1503/cmaj.170910

\begin{abstract}
BACKGROUND: The effectiveness of repeated vaccination for influenza to prevent severe cases remains unclear. We evaluated the effectiveness of influenza vaccination on preventing admissions to hospital for influenza and reducing disease severity.
\end{abstract}

METHODS: We conducted a case-control study in 20 hospitals in Spain during the 2013/14 and 2014/15 influenza seasons. Community-dwelling adults aged 65 years or older who were admitted to hospital for laboratory-confirmed influenza were matched with inpatient controls by sex, age, hospital and admission date. The effectiveness of vaccination in the current and 3 previous seasons in preventing influenza was estimated for inpatients with nonsevere influenza and for those with severe influenza who were admitted to intensive care units (ICUs) or who died.

RESULTS: We enrolled 130 inpatients with severe and 598 with nonsevere influenza who were matched to 333 and 1493 controls, respectively. Compared with patients who were unvaccinated in the current and 3 previous seasons, adjusted effectiveness of influenza vaccination in the current and any previous season was 31\% (95\% confidence interval [Cl] $13 \%-46 \%$ ) in preventing admission to hospital for nonsevere influenza, $74 \%$ (95\% Cl 42\%-88\%) in preventing admissions to ICU and $70 \%(95 \% \mathrm{CI}$ $34 \%-87 \%$ ) in preventing death. Vaccination in the current season only had no significant effect on cases of severe influenza. Among inpatients with influenza, vaccination in the current and any previous season reduced the risk of severe outcomes (adjusted odds ratio $0.45,95 \% \mathrm{Cl} 0.26-0.76$ ).

INTERPRETATION: Among older adults, repeated vaccination for influenza was twice as effective in preventing severe influenza compared with nonsevere influenza in patients who were admitted to hospital, which is attributable to the combination of the number of admissions to hospital for influenza that were prevented and reduced disease severity. These results reinforce recommendations for annual vaccination for influenza in older adults. easonal influenza has a large effect on admissions to hospital and deaths among older adults. ${ }^{1,2}$ Influenza vaccination is effective in preventing visits to primary health care and hospital admissions for laboratory-confirmed influenza, ${ }^{3-6}$ but there is little research available on the effectiveness of influenza vaccination on severe and fatal laboratoryconfirmed influenza. ${ }^{5}$

Age-related changes in the immune system, major chronic conditions and risk factors may interfere with and hamper a successful vaccine response in older adults. ${ }^{7}$ When influenza vaccination fails to prevent illness caused by influenza, studies have suggested that vaccination may still have an additional effect by reducing the severity of disease. ${ }^{5,8-13}$ This vaccine effect would be of great interest among older adults, in whom the effectiveness of influenza vaccination is normally suboptimal and severe influenza is more frequent. ${ }^{1,6,7}$

Influenza vaccination in previous seasons may retain some preventive effectiveness, ${ }^{14-17}$ and new doses may boost the preexisting immune memory against antigenically related strains. ${ }^{16,18}$ However, a negative interference between vaccination in the current and previous seasons has been described. ${ }^{19-22}$ Yet, no studies have evaluated the effectiveness of repeated influenza vaccination in preventing severe influenza, although older adults may accumulate many doses of vaccine over the seasons. The present study aimed to estimate the effectiveness of influenza vaccines that were received in the current and 3 previous seasons in preventing severe cases of influenza in older patients. We also sought to differentiate vaccine effectiveness in preventing illness caused by influenza, and the 
effect on reducing the risk of admission to the intensive care unit (ICU) and death when influenza vaccination failed to prevent admission to hospital for influenza.

\section{Methods}

\section{Study population and design}

We conducted a matched case-control study in 20 tertiary hospitals in Spain during the 2013/14 and 2014/15 influenza seasons. ${ }^{23}$ The trivalent inactivated influenza vaccine was recommended and offered free of charge to all people aged 65 years and older. Patients admitted with influenza-like illness or acute respiratory disease in participant hospitals were routinely swabbed regardless of disease severity or vaccination status.

We included patients aged 65 years or older who were admitted to hospital for more than 24 hours with influenza confirmed by reverse transcription polymerase chain reaction, culture or immunofluorescence. We excluded patients living in long-term care facilities, and patients who had symptom onset after being admitted to hospital or with unknown vaccination status.

We selected up to 3 matched controls per case from patients aged 65 years or older with an unplanned admission to hospital to the internal medicine, general surgery, otorhinolaryngology, ophthalmology, dermatology or traumatology services in the same hospital for causes other than influenza or acute respiratory disease. Controls were matched with each patient by sex, age ( $\pm 3 \mathrm{yr}$ ), date of admission to hospital ( $\pm 10 \mathrm{~d}$ ) and hospital.

\section{Data collection}

A structured questionnaire was used by trained health professionals to collect baseline data from patients with influenza and those in the control group by interview and review of medical records. This included sociodemographic data, functional status (Barthel Index score), smoking, major chronic conditions (pulmonary disease, renal disease, diabetes, immunocompromising conditions, neurologic disease, cancer, chronic liver disease, cardiovascular disease, neuromuscular disease, cognitive dysfunction, rheumatologic disease and body mass index $\left.\geq 40 \mathrm{~kg} / \mathrm{m}^{2}\right)$, other preexisting risk factors for influenza severity (pneumonia in the previous $2 \mathrm{yr}$ and treatment with corticosteroids administered orally at a dosage of $>20 \mathrm{mg} / \mathrm{d}$ for $>14 \mathrm{~d}$ in the last month) and use of health services in the previous year. We collected information from medical records on laboratory diagnosis, symptom onset, dates of hospital admission and discharge, treatment with antiviral drugs, admission to ICU and death within 30 days after admission to hospital.

Information on vaccination status, including seasonal influenza vaccination in the current and 3 previous seasons, 23-valent polysaccharide pneumococcal vaccination and 13-valent pneumococcal conjugate vaccination, was obtained from medical records and regional vaccination registers. Patients were classified according to influenza vaccination status in the current and 3 previous influenza seasons in 4 categories: unvaccinated in the current and previous seasons (reference), unvaccinated in the current season and vaccinated in any previous season, vaccinated in the current season and unvaccinated in previous seasons, and vaccinated in the current and in any previous season.

\section{Statistical analysis}

We defined patients with severe illness from influenza that required admission to hospital as patients who required admission to the ICU or who died within 30 days after admission to hospital. This definition has relevant implications, is easy to apply and to compare, and has been used previously., $5,811,12$

We compared baseline characteristics between patients with influenza and controls, patients with nonsevere and severe illness, and vaccinated and unvaccinated patients with influenza. We used the $\chi^{2}$ and Fisher exact tests for categorical variables and the $t$ test for continuous variables. We considered values of $p$ less than 0.05 for 2 -tailed tests as significant.

We estimated the effectiveness of influenza vaccination in preventing patient admission to hospital for influenza by comparing patients with nonsevere influenza with matched controls, and the total effect of influenza vaccination in preventing severe illness from influenza was estimated by comparing patients with severe influenza with their matched controls (Figure 1). In both analyses, we compared the vaccination status of patients with influenza and matched controls using conditional logistic regression to obtain crude and adjusted odds ratios (ORs) with $95 \%$ confidence intervals (Cls). Models were adjusted for major chronic conditions, previous pneumonia, treatment with corticosteroids, pneumococcal vaccination, functional dependence, and primary care and hospital visits in the previous year.

We estimated the effectiveness of crude and adjusted vaccination in reducing severity of illness among patients with influenza by comparing the influenza vaccination status of patients with severe and nonsevere influenza who were admitted to hospital for influenza (case-to-case analysis) using unconditional logistic regression (Figure 1). The adjusted models included sex, age, hospital site, influenza season and all previously mentioned variables.

Estimates were made for the prevention of all severe forms of influenza, and separately for admissions to ICU and 30-day mortality. We estimated effectiveness of vaccination as $(1$ - adjusted OR $) \times 100$.

We conducted sensitivity analyses in patient subgroups by sex, chronic conditions, functional dependence, time from symptom onset to admission to hospital, pneumococcal vaccination and treatment with antiviral drugs.

\section{Ethics approval}

The study was approved by the ethics committees of the participating hospitals. Written informed consent was obtained from all patients who were included in the study.

\section{Results}

\section{Description of the study population}

We enrolled 728 patients with influenza who were admitted to hospital. Influenza $A(H 1 N 1) p d m 09$ was confirmed in 325 patients, $A(H 3 N 2)$ in 256 , A nonsubtyped in 106, influenza $B$ in 39 and no type was available for 2 patients. Influenza $A(H 1 N 1)$ pdm09 was dominant in season 2013/14 and A(H3N2) in season 2014/15. Of the patients with influenza who were admitted to hospital, 77 were admitted to ICU and 83 died within 30 days 


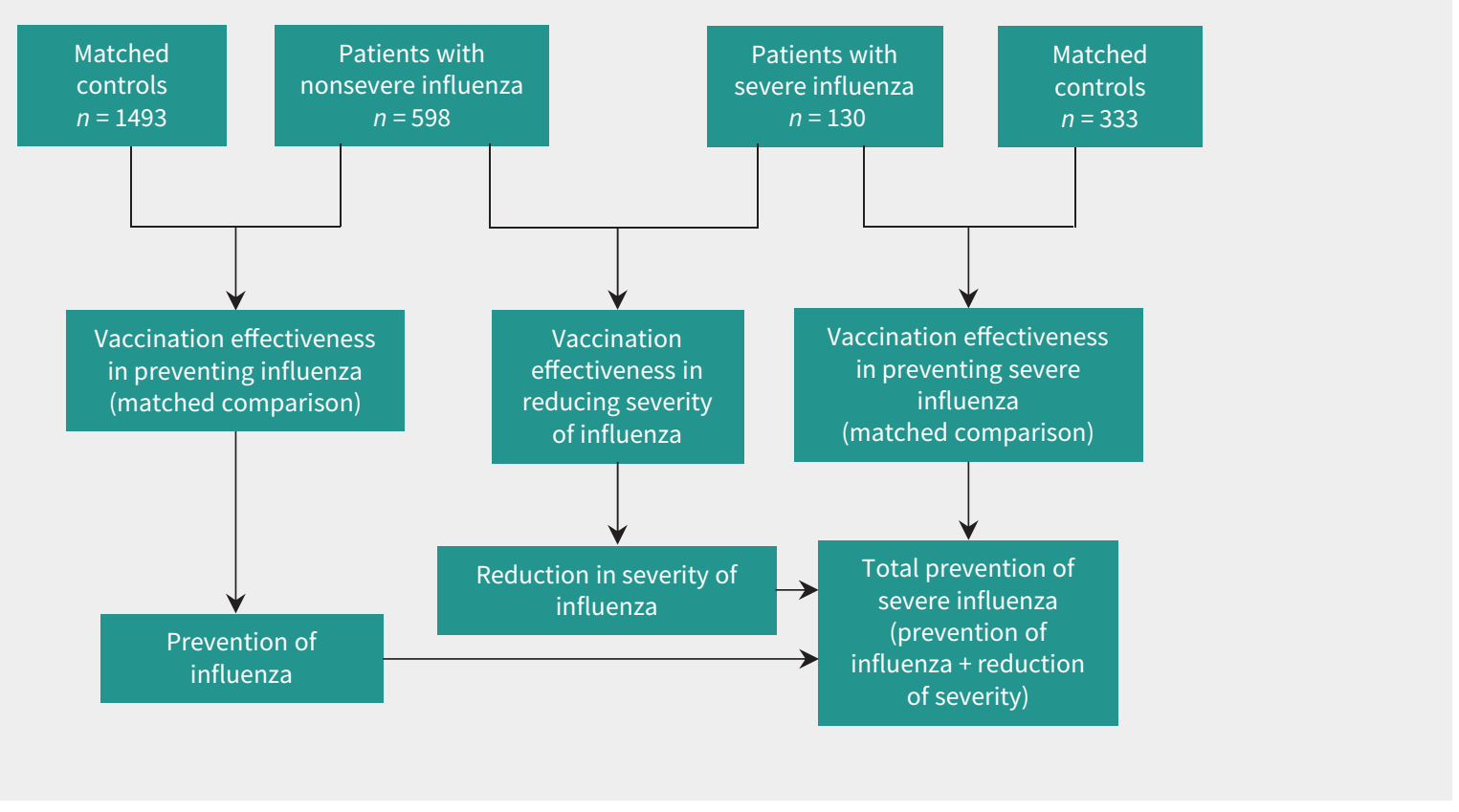

Figure 1: Scheme of the study groups and the comparisons made.

after hospital admission. Thirty patients died after being admitted to ICU. Therefore, we matched 130 patients with severe and 598 with nonsevere influenza individually to 333 and 1493 controls, respectively (Figure 1 ).

Baseline characteristics of patients with severe influenza did not differ from those of their matched controls, except for a higher frequency of chronic pulmonary disease, previous pneumonia and treatment with corticosteroids, and lower coverage of influenza vaccination in the current and previous seasons. Patients with nonsevere influenza had lower coverage of influenza vaccination in the current season, but not in previous seasons, compared with their matched controls. Patients with severe influenza had a higher frequency of cardiovascular disease, had received primary care services less often, had longer mean hospital stays and were vaccinated less frequently than patients with nonsevere influenza in the current and 3 previous seasons (Table 1 ).

Patients with influenza who were unvaccinated were admitted more frequently to ICU $(16 \%$ v. $6 \%, p<0.001)$ and had more deaths in the 30 days after hospital admission (14\% v. $9 \%, p=$ 0.04) (Table S1 in Appendix 1, available at www.cmaj.ca/lookup/ suppl/doi:10.1503/cmaj.170910/-/DC1).

\section{Effectiveness of vaccination for influenza on prevention of admission to hospital for influenza}

In comparison with patients who were unvaccinated in the current and 3 previous seasons, influenza vaccination in the current and any previous season was $31 \%$ (95\% Cl $13 \%$ to $46 \%$ ) effective in preventing admissions to hospital for nonsevere influenza. Nevertheless, the estimates of effectiveness were higher for preventing admission to the ICU because of influenza $(74 \%, 95 \% \mathrm{CI}$
$42 \%$ to $88 \%)$ and for preventing death $(70 \%, 95 \% \mathrm{Cl} 34 \%$ to $87 \%)$. Vaccination that occurred only in the current season did not show significant protection against severe influenza $(-1 \%$, $95 \% \mathrm{Cl}-147 \%$ to $59 \%$ ) (Figure 2 ).

We evaluated the effectiveness of vaccination in the current and any previous season using sensitivity analyses stratified by influenza season, influenza A virus subtype and age group, and the results were generally similar, with modest effect estimates against nonsevere influenza and greater effect estimates against severe forms (Figure 3).

The number of doses of influenza vaccine that accumulated in the current and 3 previous seasons was associated with a progressive reduction in the risk of admission to hospital for severe influenza ( $p$ for linear trend $<0.001$ ), but no similar trend was observed for admission to hospital for nonsevere influenza (Table S2 in Appendix 2, available at www.cmaj.ca/lookup/suppl/ doi:10.1503/cmaj.170910/-/DC1). The effectiveness of vaccination in the current season against illness caused by severe influenza increased when associated with previous vaccination, but no similar pattern was observed against illness caused by nonsevere forms (Table S3 in Appendix 3, available at www.cmaj.ca/ lookup/suppl/doi:10.1503/cmaj.170910/-/DC1).

\section{Effectiveness of vaccination for influenza on reducing severity}

In patients admitted to hospital for influenza, vaccination in the current and any of the 3 previous seasons was associated with $55 \%$ lower odds of severity of disease (adjusted OR $0.45,95 \% \mathrm{CI}$ 0.26 to 0.76 ), $65 \%$ of admission to the ICU (adjusted OR 0.35, $95 \% \mathrm{Cl} 0.17$ to 0.70 ) and $56 \%$ of death (adjusted OR $0.44,95 \% \mathrm{Cl}$ 0.23 to 0.86 ). However, vaccination in the current season only 
Table 1: Baseline patient characteristics, and comparison of patients admitted to hospital with nonsevere and severe influenza with patients in the control group

\begin{tabular}{|c|c|c|c|c|c|c|c|}
\hline Characteristic & $\begin{array}{c}\text { No. }(\%) \text { of } \\
\text { patients with } \\
\text { nonsevere } \\
\text { influenza* } \\
n=598\end{array}$ & $\begin{array}{c}\text { No. }(\%) \text { of } \\
\text { patients in the } \\
\text { control group* } \\
n=1493\end{array}$ & $\begin{array}{c}p \text { valuet } \\
\text { (patients with } \\
\text { nonsevere } \\
\text { influenza v. } \\
\text { controls) }\end{array}$ & $\begin{array}{l}\text { No. }(\%) \text { of } \\
\text { patients with } \\
\text { severe } \\
\text { influenza* } \\
n=130\end{array}$ & $\begin{array}{l}\text { No. }(\%) \text { of } \\
\text { patients in the } \\
\text { control group } \\
\quad n=333\end{array}$ & $\begin{array}{c}p \text { valuet } \\
\text { (patients } \\
\text { with severe } \\
\text { influenza v. } \\
\text { controls) }\end{array}$ & $\begin{array}{c}\quad p \text { value } \neq \\
\text { (patients with } \\
\text { severe v. those } \\
\text { with nonsevere } \\
\text { influenza) }\end{array}$ \\
\hline Influenza season & & & 0.3 & & & 0.5 & 0.9 \\
\hline 2013/14 & $355(59.4)$ & 849 (56.9) & & $78(60.0)$ & $189(56.8)$ & & \\
\hline Female & $279(46.7)$ & $716(48.0)$ & & $64(49.2)$ & $168(50.5)$ & & \\
\hline Male & $319(53.3)$ & $777(52.0)$ & & $66(50.8)$ & $165(49.5)$ & & \\
\hline Age, yr & & & 0.7 & & & 0.9 & 0.6 \\
\hline 65-79 & $340(56.9)$ & $837(56.1)$ & & $71(54.6)$ & $179(53.8)$ & & \\
\hline$\geq 80$ & $258(43.1)$ & 656 (43.9) & & $59(45.4)$ & $154(46.2)$ & & \\
\hline$>1$ & $325(54.3)$ & $783(52.4)$ & & $85(65.4)$ & $191(57.4)$ & & \\
\hline Pulmonary disease & $262(43.8)$ & $362(24.2)$ & $<0.001$ & $55(42.3)$ & $91(27.3)$ & 0.002 & 0.8 \\
\hline Diabetes & $187(31.3)$ & $542(36.3)$ & 0.03 & $48(36.9)$ & $124(37.2)$ & 1 & 0.2 \\
\hline Cardiovascular disease & $162(27.1)$ & $498(33.4)$ & 0.005 & $62(47.7)$ & $153(45.9)$ & 0.7 & $<0.001$ \\
\hline $\begin{array}{l}\text { Pneumonia in the } \\
\text { previous } 2 \mathrm{yr}\end{array}$ & $72(12.0)$ & $82(5.5)$ & $<0.001$ & $19(14.6)$ & $22(6.6)$ & 0.006 & 0.4 \\
\hline $\begin{array}{l}\text { Corticosteroid treatment } \\
\text { in the previous month }\end{array}$ & $33(5.5)$ & $35(2.3)$ & $<0.001$ & $11(8.5)$ & $8(2.4)$ & 0.003 & 0.2 \\
\hline Barthel Index score $<40$ & $50(8.4)$ & $153(10.2)$ & 0.2 & $16(12.3)$ & $32(9.6)$ & 0.4 & 0.2 \\
\hline Smoking & & & 0.2 & & & 0.1 & 0.8 \\
\hline Never smoked & $316(52.8)$ & $851(57.0)$ & & $67(51.5)$ & 206 (61.9) & & \\
\hline $\begin{array}{l}\text { Visited hospital in } \\
\text { previous year }\end{array}$ & $411(69.2)$ & $1094(73.7)$ & 0.04 & $94(75.2)$ & $235(71.9)$ & 0.5 & 0.2 \\
\hline $\begin{array}{l}\text { Admission to hospital } \geq 7 \mathrm{~d} \\
\text { within onset }\end{array}$ & $133(22.2)$ & NA & & $20(15.4)$ & NA & & 0.08 \\
\hline $\begin{array}{l}\text { Length of hospital stay, } \\
\text { mean } \pm \mathrm{SD} \text {; d }\end{array}$ & $10 \pm 9$ & $13 \pm 11$ & $<0.001$ & $17 \pm 14$ & $14 \pm 12$ & 0.02 & $<0.001$ \\
\hline Antiviral treatment & $521(88.9)$ & NA & & $119(92.2)$ & NA & & 0.3 \\
\hline \multicolumn{8}{|l|}{ Pneumococcal vaccination } \\
\hline $\begin{array}{l}\text { 23-Valent polysaccharide } \\
\text { vaccine }\end{array}$ & $117(19.6)$ & $221(14.8)$ & 0.008 & $18(13.8)$ & $56(16.8)$ & 0.4 & 0.1 \\
\hline 13-Valent conjugate vaccine & $12(2.0)$ & $11(0.7)$ & 0.01 & $1(0.8)$ & $2(0.6)$ & 1 & 0.3 \\
\hline $\begin{array}{l}\text { Current season influenza } \\
\text { vaccination }\end{array}$ & $312(52.2)$ & $862(57.7)$ & 0.02 & $47(36.2)$ & $191(57.4)$ & $<0.001$ & 0.001 \\
\hline \multicolumn{8}{|c|}{ Prior season influenza vaccination } \\
\hline Current season - 1 & $329(55.0)$ & $872(58.4)$ & 0.2 & $47(36.2)$ & $182(54.7)$ & $<0.001$ & $<0.001$ \\
\hline Current season - 2 & $327(54.7)$ & $846(56.7)$ & 0.4 & $51(39.2)$ & $186(55.9)$ & 0.001 & 0.001 \\
\hline Current season - 3 & $324(54.2)$ & $823(55.1)$ & 0.7 & $48(36.9)$ & $171(51.4)$ & 0.005 & $<0.001$ \\
\hline $\begin{array}{l}\text { Note: } \mathrm{NA}=\text { not applicable, } \mathrm{SD}=\text { sta } \\
\text { *Unless stated otherwise. } \\
\text { †Comparison of patients with influ } \\
\text { †Comparison of patients with seve } \\
\text { \$Chronic diseases that were pre } \\
\text { disease, body mass index } \geq 40 \mathrm{k}\end{array}$ & $\begin{array}{l}\text { deviation. } \\
\text { and controls ( } \\
\text { d nonsevere ir } \\
\text { at baseline, it } \\
\text { cardiovascu }\end{array}$ & $\begin{array}{l}\text { Imitted to hos } \\
\text { ing the } \chi^{2} \text { tes } \\
\text { ulmonary d } \\
\text { e, neuromus }\end{array}$ & $\begin{array}{l}\text { e } \chi^{2} \text { test, } \mathrm{Fi} \\
\text { test or } t \text { test } \\
\text { disease, di } \\
\text {, cognitive }\end{array}$ & $t$ test or $t$ test. & n & 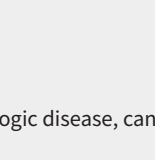 & $r$ \\
\hline
\end{tabular}


showed no reduced odds of severe disease and increased odds of death (adjusted OR $3.35,95 \% \mathrm{Cl} 1.06$ to 10.58) (Table 2), which is consistent with a preventive effect against nonsevere influenza but not against severe influenza.

We evaluated the effectiveness of influenza vaccination for reducing disease severity in analyses stratified by season, virus subtype, age, sex, chronic conditions, functional status, timing of admission to hospital, pneumococcal vaccination and treatment with antiviral drugs, and most analyses supported the consistency of the results (Table 3 ).

\section{Interpretation}

Our multicentre study comprehensively evaluated and integrated the effectiveness of repeated influenza vaccination in preventing admissions to hospital for influenza and in reducing disease severity. We found that repeated influenza vaccination was twice as effective in preventing severe cases of laboratoryconfirmed influenza that required admission to hospital in older patients compared with nonsevere cases, with consistent results irrespective of the influenza season, virus subtype and age. Estimates were similar for patients admitted to the ICU and 30-day mortality. Because vaccine effectiveness in preventing infection caused by influenza is not expected to be higher for patients admitted to hospital with severe influenza than for those admitted with nonsevere influenza, the greater effectiveness observed in patients with severe influenza may be explained by the effectiveness of vaccination in reducing the risk of severe outcomes. Unlike the direct prevention of illness caused by influenza, the reduction in severity of illness caused by influenza required vaccination in the current and previous seasons, and showed a dose-response relation.

During these 2 seasons, the main circulating viruses matched the vaccine strains in Spain and other countries in Europe, ${ }^{24,25}$ which contrasted with the low effectiveness of vaccination that was observed against nonsevere influenza; ${ }^{26}$ however, this was consistent with the greater effectiveness that we found against severe influenza.

The effectiveness of influenza vaccination in reducing disease severity may become evident by onset of less severe illness or by reduced progression to severe illness. ${ }^{8}$ In both cases, the effect would appear as a lower frequency of severe outcomes in vaccinated patients with influenza who were admitted to hospital-than in those who were unvaccinated and would have been detected in our study.

Although protection against infection caused by influenza has been related primarily to antibodies, protection against severe outcomes may be mediated through cellular immune responses. ${ }^{27} \mathrm{~T}$ cells, which mediate cellular immune responses, can target internal proteins common to heterologous viral strains. This gives vaccines that induce protective cellular immune responses the potential to protect against heterologous viral strains. ${ }^{27,28}$ Cell-mediated immunity against the influenza virus may be impaired in older adults, and this may contribute to

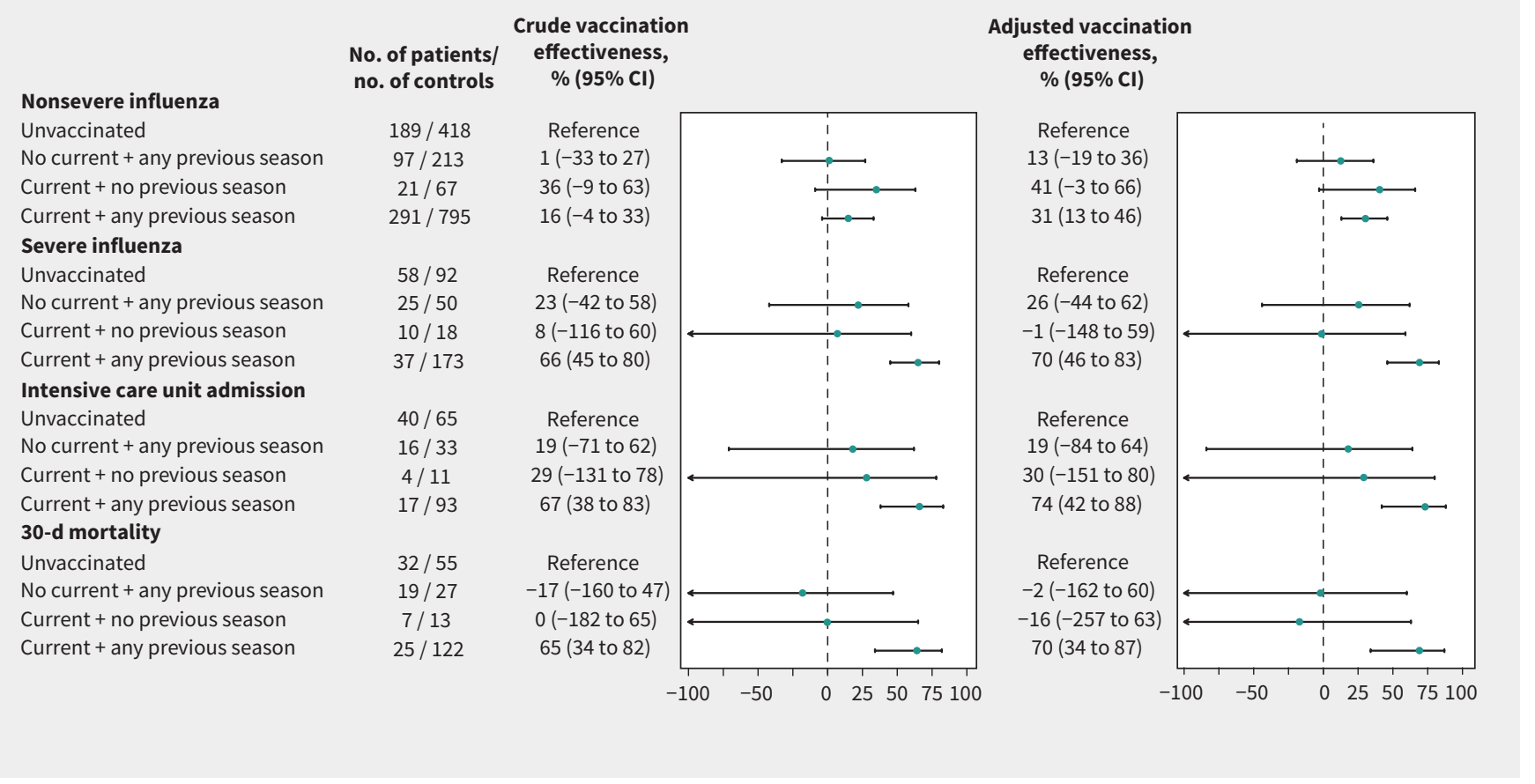

Figure 2: Effectiveness of vaccination for influenza in the current and 3 previous seasons in preventing nonsevere and severe cases of influenza. Estimates were obtained from conditional logistic regression models. The adjusted models included the number of chronic conditions, Barthel Index score, number of visits to primary care and hospital in the previous year, pneumococcal vaccination, diagnosis of pneumonia in the previous 2 years and treatment with corticosteroids administered orally in the previous month. Note: $\mathrm{Cl}=$ confidence interval. Values $>0$ represent the preventive effect of vaccination. 
greater disease severity when the patient acquires infection; ${ }^{29}$ however, our results suggest that the effect against disease severity may be improved by repeated vaccination.

Our results for the reduction in disease severity in patients with influenza who were admitted to hospital are consistent with other studies. High vaccine effectiveness in preventing severe cases of influenza was reported in the $2010 / 11$ season in Spain, and vaccination was associated with a reduced risk of severe outcomes in patients admitted to hospital for influenza. ${ }^{5} \mathrm{~A}$ study in the United States reported that patients who required admis-

\begin{tabular}{|c|c|c|c|}
\hline & \multicolumn{2}{|c|}{$\begin{array}{l}\text { No. of vaccinated } \\
\text { /no. of unvaccinated }\end{array}$} & \multirow{2}{*}{$\begin{array}{l}\text { Adjusted vaccina } \\
\text { effectiveness } \\
\%(95 \% \mathrm{CI})\end{array}$} \\
\hline & Patients & Controls & \\
\hline \multicolumn{4}{|c|}{ All patients admitted to hospital } \\
\hline Nonsevere influenza & $291 / 189$ & 795 / 418 & 31 (13 to 46$)$ \\
\hline Severe influenza & $37 / 58$ & $173 / 92$ & 70 (46 to 83 ) \\
\hline ICU admission & $17 / 40$ & $93 / 65$ & 74 (42 to 88$)$ \\
\hline 30-d mortality & $25 / 32$ & $122 / 55$ & 70 (34 to 87 ) \\
\hline \multicolumn{4}{|l|}{ Season $2013 / 14$} \\
\hline Nonsevere influenza & $167 / 116$ & $446 / 229$ & 28 (1 to 47$)$ \\
\hline Severe influenza & $21 / 38$ & 94 / 57 & 74 (44 to 88 ) \\
\hline ICU admission & $13 / 23$ & $43 / 42$ & $59(-8$ to 84$)$ \\
\hline 30-d mortality & $11 / 23$ & $71 / 32$ & 84 (53 to 95$)$ \\
\hline \multicolumn{4}{|l|}{ Season $2014 / 15$} \\
\hline Nonsevere influenza & $124 / 73$ & $349 / 189$ & 36 (5 to 57$)$ \\
\hline Severe influenza & $16 / 20$ & $79 / 35$ & $63(-5$ to 87$)$ \\
\hline ICU admission & $4 / 17$ & $50 / 23$ & 95 (55 to 99) \\
\hline 30-d mortality & $14 / 9$ & $51 / 23$ & $36(-145$ to 83$)$ \\
\hline \multicolumn{4}{|l|}{ H1N1pdm09 } \\
\hline Nonsevere influenza & $109 / 92$ & $321 / 172$ & 47 (24 to 64$)$ \\
\hline Severe influenza & $17 / 38$ & 102 / 60 & 75 (45 to 89 ) \\
\hline ICU admission & $9 / 27$ & $61 / 44$ & 79 (40 to 93$)$ \\
\hline 30-d mortality & $12 / 22$ & $76 / 37$ & 72 (18 to 91 ) \\
\hline \multicolumn{4}{|l|}{ H3N2 } \\
\hline Nonsevere influenza & $114 / 60$ & 317 / 153 & 21 (-18 to 47$)$ \\
\hline Severe influenza & $11 / 15$ & $45 / 25$ & 74 (10 to 93 ) \\
\hline ICU admission & $5 / 9$ & $22 / 16$ & $85(-13$ to 98$)$ \\
\hline 30-d mortality & $7 / 8$ & $28 / 15$ & 77 (58 to 97 ) \\
\hline \multicolumn{4}{|l|}{ Aged 65-79 yr } \\
\hline Nonsevere influenza & $145 / 118$ & 422 / 62 & 38 (15 to 55$)$ \\
\hline Severe influenza & $19 / 37$ & $86 / 59$ & 68 (31 to 86 ) \\
\hline ICU admission & $12 / 31$ & $61 / 50$ & 71 (28 to 88 ) \\
\hline 30-d mortality & $11 / 16$ & $49 / 30$ & 86 (11 to 98$)$ \\
\hline \multicolumn{4}{|l|}{ Aged $>79 \mathrm{yr}$} \\
\hline Nonsevere influenza & $146 / 71$ & $373 / 150$ & 25 (-9 to 48$)$ \\
\hline Severe influenza & $18 / 21$ & $87 / 33$ & 77 (39 to 91) \\
\hline ICU admission & $5 / 9$ & $32 / 15$ & $98(-30$ to 100$)$ \\
\hline 30-d mortality & $14 / 16$ & $13 / 25$ & 77 (34 to 92) \\
\hline
\end{tabular}

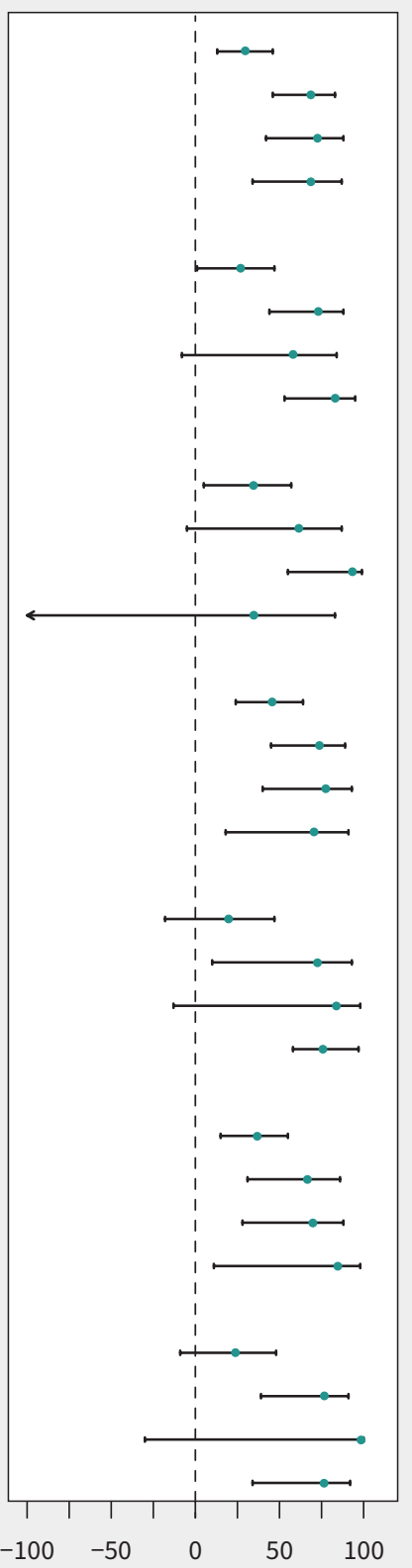

Figure 3: Effectiveness of vaccination for influenza in the current and any of the 3 previous seasons in preventing nonsevere and severe cases of influenza by season, virus subtype and age group. Estimates were obtained from conditional logistic regression models. The adjusted models included the number of chronic conditions, Barthel Index score, number of visits to primary care and hospital attendance in the previous year, pneumococcal vaccination, diagnosis of pneumonia in the previous 2 years and reatment with corticosteroids administered orally in the previous month. $\mathrm{Note}$ : $\mathrm{Cl}=$ confidence interval. Values $>0$ represent the preventive effect of vaccination. 
sion to the ICU had lower influenza vaccine coverage, ${ }^{9}$ and another found that influenza vaccination was associated with a reduction in the odds of in-hospital death and admission to the ICU among community-dwelling adults who were admitted to hospital with confirmed influenza. ${ }^{8}$ Recent studies in Spain ${ }^{11}$ and France $^{12}$ that involved adults admitted to hospital for influenza reported that seasonal vaccination reduced the risk of severe outcomes. Our results and the results from these other studies suggest that influenza vaccination reduces severity of disease among older patients in whom vaccination did not prevent illness caused by influenza.

Influenza vaccination in successive seasons was necessary to prevent severe influenza that required admission to hospital in older adults. In seasons with suboptimal effectiveness of the influenza vaccine in protecting people from contracting illness owing to influenza, the vaccine effect in reducing disease severity may be fundamental. These results and those from other studies reinforce the recommendation of annual influenza vaccination in older adults. ${ }^{30}$
The strengths of our study included the multicentre prospective design, recruitment over 2 consecutive influenza seasons regardless of the vaccination status or disease severity, data collection following a standardized protocol, vaccination status obtained from clinical records or vaccination registers, and inclusion of laboratory-confirmed cases only. The sensitivity analyses showed the robustness of the results.

\section{Limitations}

The study had some possible limitations. Bias frequently affects case-control studies; however, the consistency of findings from the 2 matched case-control designs and the case-to-case comparison suggests a lack of relevant residual bias. The estimate of vaccination effectiveness in patients with nonsevere influenza was within the range of the effectiveness that was reported in a multicentre European study for the same seasons. ${ }^{26}$

Interviewers in our study knew whether the patients being interviewed had influenza or not, and this could have influenced information gathering. Nevertheless, most data were obtained

Table 2: Effects of infuenza vaccination status in the current and 3 previous seasons in reducing severity of illness in patients who were admitted to hospital for influenza

\begin{tabular}{|c|c|c|c|c|}
\hline Analysis subset & $\begin{array}{l}\text { No. of patients with severe } \\
\text { influenza/no. of patients } \\
\text { with nonsevere influenza }\end{array}$ & $\begin{array}{l}\text { Crude OR } \\
(95 \% \mathrm{CI})^{\star}\end{array}$ & $\begin{array}{l}\text { Adjusted OR } \\
(95 \% \mathrm{CI})^{\star}\end{array}$ & $p$ value \\
\hline \multicolumn{5}{|l|}{ All patients with severe influenza } \\
\hline Unvaccinated in the current and previous seasons & $58 / 189$ & Ref. & Ref. & \\
\hline Unvaccinated in the current and vaccinated in any previous season & $25 / 97$ & $\begin{array}{c}0.84 \\
(0.49-1.43)\end{array}$ & $\begin{array}{c}0.79 \\
(0.43-1.43)\end{array}$ & 0.4 \\
\hline Vaccinated in the current and unvaccinated in previous seasons & $10 / 21$ & $\begin{array}{c}1.55 \\
(0.69-3.48)\end{array}$ & $\begin{array}{c}2.22 \\
(0.89-5.51)\end{array}$ & 0.09 \\
\hline Vaccinated in the current and any previous season & $37 / 291$ & $\begin{array}{c}0.41 \\
(0.26-0.65)\end{array}$ & $\begin{array}{c}0.45 \\
(0.26-0.76)\end{array}$ & 0.003 \\
\hline \multicolumn{5}{|l|}{ All patients with influenza who were admitted to ICU } \\
\hline Unvaccinated in the current and previous seasons & $40 / 189$ & Ref. & Ref. & \\
\hline Unvaccinated in the current and vaccinated in any previous season & $16 / 97$ & $\begin{array}{c}0.78 \\
(0.42-1.46)\end{array}$ & $\begin{array}{c}0.74 \\
(0.37-1.50)\end{array}$ & 0.4 \\
\hline Vaccinated in the current and unvaccinated in previous seasons & $4 / 21$ & $\begin{array}{c}0.90 \\
(0.29-2.77)\end{array}$ & $\begin{array}{c}1.14 \\
(0.34-3.87)\end{array}$ & 0.8 \\
\hline Vaccinated in the current and any previous season & $17 / 291$ & $\begin{array}{c}0.28 \\
(0.15-0.50)\end{array}$ & $\begin{array}{c}0.35 \\
(0.17-0.70)\end{array}$ & 0.003 \\
\hline \multicolumn{5}{|l|}{ Patients with influenza who died within $\mathbf{3 0} \mathrm{d}$ after hospital admission } \\
\hline Unvaccinated in the current and previous seasons & $32 / 189$ & Ref. & Ref. & \\
\hline Unvaccinated in the current and vaccinated in any previous season & $19 / 97$ & $\begin{array}{c}1.16 \\
(0.62-2.15)\end{array}$ & $\begin{array}{c}1.09 \\
(0.52-2.31)\end{array}$ & 0.8 \\
\hline Vaccinated in the current and unvaccinated in previous seasons & $7 / 21$ & $\begin{array}{c}1.97 \\
(0.77-5.51)\end{array}$ & $\begin{array}{c}3.35 \\
(1.06-10.58)\end{array}$ & 0.04 \\
\hline Vaccinated in the current and any previous season & $25 / 291$ & $\begin{array}{c}0.51 \\
(0.29-0.88)\end{array}$ & $\begin{array}{c}0.44 \\
(0.23-0.86)\end{array}$ & 0.02 \\
\hline
\end{tabular}


from medical records. Patients in both the case and control groups were included in the study when they sought medical treatment, which could have made them more similar in the use of health services. The estimates could be affected if vaccinated patients went to hospital sooner than unvaccinated patients; however, the adjusted analysis by primary health care and hospital visits in the last year, and the analysis of patients admitted in the first 7 days after symptom onset ruled out relevant bias.

Table 3: Effectiveness of Influenza vaccination in reducing disease severity in patients with influenza who were admitted to hospital for the current and any previous season

\begin{tabular}{|c|c|c|c|c|}
\hline Analysis subset & $\begin{array}{l}\text { No. of patients with } \\
\text { severe influenza } \\
\text { (\% vaccinated) }\end{array}$ & $\begin{array}{l}\text { No. of patients with } \\
\text { nonsevere influenza } \\
\text { (\% vaccinated) }\end{array}$ & $\begin{array}{l}\text { Crude OR } \\
(95 \% \mathrm{CI})\end{array}$ & $\begin{array}{c}\text { Adjusted OR } \\
(95 \% \mathrm{CI})^{\star}\end{array}$ \\
\hline Primary analysis & $130(28.5)$ & $598(48.7)$ & $0.41(0.26-0.65)$ & $0.45(0.26-0.76)$ \\
\hline \multicolumn{5}{|l|}{ Influenza season } \\
\hline $2013 / 14$ & $78(26.9)$ & $355(47.0)$ & $0.38(0.21-0.69)$ & $0.35(0.17-0.74)$ \\
\hline $2014 / 15$ & $52(30.8)$ & $243(51.0)$ & $0.47(0.23-0.97)$ & $0.69(0.28-1.72)$ \\
\hline \multicolumn{5}{|l|}{ Type of influenza virus } \\
\hline A/H1N1pdm09 & $79(21.5)$ & $246(44.3)$ & $0.38(0.20-0.71)$ & $0.31(0.13-0.71)$ \\
\hline A/H3N2 & $34(32.4)$ & $222(51.4)$ & $0.39(0.17-0.89)$ & $0.32(0.12-0.89)$ \\
\hline \multicolumn{5}{|l|}{ Sex } \\
\hline Female & $64(18.8)$ & $279(46.2)$ & $0.26(0.13-0.53)$ & $0.27(0.11-0.67)$ \\
\hline Male & $66(37.9)$ & $319(50.8)$ & $0.59(0.32-1.07)$ & $0.63(0.30-1.31)$ \\
\hline \multicolumn{5}{|l|}{ Age, yr } \\
\hline $65-79$ & $71(26.8)$ & $340(42.6)$ & $0.42(0.23-0.76)$ & $0.43(0.20-0.91)$ \\
\hline$\geq 80$ & $59(30.5)$ & $258(56.6)$ & $0.42(0.21-0.83)$ & $0.42(0.17-1.02)$ \\
\hline \multicolumn{5}{|l|}{ Major chronic conditions $\dagger$} \\
\hline None & $14(35.7)$ & $76(36.8)$ & $0.74(0.22-2.51)$ & $0.40(0.03-5.37)$ \\
\hline Any & $116(27.6)$ & $522(50.4)$ & $0.38(0.23-0.62)$ & $0.39(0.22-0.69)$ \\
\hline Pulmonary disease & $55(36.4)$ & $262(53.4)$ & $0.52(0.27-1.03)$ & $0.54(0.23-1.23)$ \\
\hline Diabetes & $48(22.9)$ & $187(48.1)$ & $0.30(0.14-0.67)$ & $0.27(0.08-0.84)$ \\
\hline Cardiovascular disease & $62(25.8)$ & $162(45.1)$ & $0.42(0.21-0.85)$ & $0.31(0.12-0.80)$ \\
\hline \multicolumn{5}{|l|}{ Barthel Index score } \\
\hline$\geq 40$ & $114(28.9)$ & $548(49.3)$ & $0.42(0.26-0.68)$ & $0.49(0.28-0.87)$ \\
\hline$<40$ & $16(25.0)$ & $50(42.0)$ & $0.38(0.09-1.55)$ & $0.04(0.00-1.55)$ \\
\hline \multicolumn{5}{|c|}{ Timing of hospital admission } \\
\hline$<7 \mathrm{~d}$ since symptom onset & $110(26.4)$ & $465(47.1)$ & $0.39(0.24-0.65)$ & $0.40(0.22-0.73)$ \\
\hline$\geq 7 \mathrm{~d}$ since symptom onset & $20(40.0)$ & $133(54.1)$ & $0.56(0.19-1.59)$ & $0.87(0.18-4.24)$ \\
\hline \multicolumn{5}{|c|}{ Pneumococcal vaccination $\ddagger$} \\
\hline Vaccinated & $19(63.2)$ & $127(67.7)$ & $2.09(0.25-17.31)$ & $1.00(0.06-15.90)$ \\
\hline Not vaccinated & $111(22.5)$ & $471(43.5)$ & $0.37(0.22-0.62)$ & $0.39(0.22-0.70)$ \\
\hline \multicolumn{5}{|l|}{ Antiviral treatment } \\
\hline Patient treated & $119(28.6)$ & $521(48.6)$ & $0.44(0.27-0.71)$ & $0.50(0.28-0.90)$ \\
\hline Patient not treated & $10(30.0)$ & $65(46.2)$ & $0.35(0.08-1.56)$ & NA \\
\hline \multicolumn{5}{|c|}{$\begin{array}{l}\text { Note: } \mathrm{Cl}=\text { confidence interval, } \mathrm{OR}=\text { odds ratio, } \mathrm{NA}=\text { not available. } \\
\text { "Estimates obtained from unconditional logistic regression models were adjusted for sex, age, number of chronic conditions, Barthel Index score, number of visits to primary care and } \\
\text { hospital in the previous year, pneumococcal vaccination, pneumonia diagnosis in the previous } 2 \text { years, treatment with corticosteroids administered orally in the previous month, } \\
\text { influenza season and hospital site. } \\
\text { tChronic diseases that were present at baseline, including pulmonary disease, renal disease, diabetes, immunocompromising conditions, neurologic disease, cancer, chronic liver } \\
\text { disease, body mass index } \geq 40 \mathrm{~kg} / \mathrm{m}^{2} \text {, cardiovascular disease, neuromuscular disease, cognitive dysfunction and rheumatologic disease. } \\
\text { tPneumococcal vaccination with } 23 \text {-valent polysaccharide vaccine in the previous } 5 \text { years or with } 13 \text {-valent conjugate vaccine. }\end{array}$} \\
\hline
\end{tabular}
severe influenza $(95 \% \mathrm{Cl})$ 
Frail patients may be less likely to be vaccinated and more likely to progress to illness of greater severity. Several points support the control of frailty bias in our study: patients with severe and nonsevere influenza were similar in many characteristics; the analysis was adjusted for frailty-related factors, such as age, chronic conditions, previous pneumonia, functional dependence and previous admission to hospital; ${ }^{31}$ patients who were either vaccinated or unvaccinated in all seasons would be less prone to frailty bias, and they were the main groups compared in this study; and the findings were consistent in separate analyses of admission to the ICU and death.

Treatment with antiviral drugs may prevent severe outcomes in patients with influenza. ${ }^{32}$ In our study, about $90 \%$ of patients with influenza received treatment with antiviral drugs; however, sensitivity analysis involving patients with and without antiviral treatment found consistent results.

Although we analyzed 2 seasons and the results are consistent with others from different countries and seasons, further studies are needed to evaluate these findings under different circumstances.

\section{Conclusion}

Repeated vaccination for influenza was highly effective in preventing severe and fatal infection caused by influenza in older adults. This high effectiveness may be explained by the combination of prevented admissions to hospital for influenza and reduced disease severity in patients admitted to hospital for influenza. Because severe cases of influenza may be prevented by 2 mechanisms, the effectiveness of vaccination against severe influenza may be greater than that for mild cases, and the benefit of influenza vaccination may be greater than that estimated in previous studies. The prevention of severe and fatal infection caused by influenza was observed mainly in patients who were vaccinated in both the current and previous seasons, which reinforces the recommendation of annual vaccination for influenza in older adults.

\section{References}

1. Thompson WW, Shay DK, Weintraub E, et al. Influenza-associated hospitalizations in the United States. JAMA 2004;292:1333-40.

2. World Health Organization. Vaccines against influenza WHO position paper November 2012. Wkly Epidemiol Rec 2012;87:461-76.

3. Kissling E, Valenciano M, Buchholz $U$, et al. Influenza vaccine effectiveness estimates in Europe in a season with three influenza type/subtypes circulating: the I-MOVE multicentre case-control study, influenza season 2012/13. Euro Surveill 2014;19:20701.

4. Havers F, Sokolow L, Shay DK, et al. Case-control study of vaccine effectiveness in preventing laboratory-confirmed influenza hospitalizations in older adults, United States, 2010-11. Clin Infect Dis 2016;63:1304-11.

5. Castilla J, Godoy P, Domínguez A, et al.; CIBERESP Cases and Controls in Influenza Working Group Spain. Influenza vaccine effectiveness in preventing outpatient, inpatient, and severe cases of laboratory-confirmed influenza. Clin Infect Dis 2013;57:167-75.

6. Darvishian M, Bijlsma MJ, Hak E, et al. Effectiveness of seasonal influenza vaccine in community-dwelling elderly people: a meta-analysis of test-negative design case-control studies. Lancet Infect Dis 2014;14:1228-39.

7. Weinberger B, Hernler-Brandstetter D, Schwanninger A, et al. Biology of immune responses to vaccines in elderly persons. Clin Infect Dis 2008;46:1078-84.
8. Arriola C, Garg S, Anderson EJ, et al. Influenza vaccination modifies disease severity among community-dwelling adults hospitalized with influenza. Clin Infect Dis 2017;65:1289-97.

9. Catania J, Que LG, Govert JA, et al. High intensive care unit admission rate for 2013-2014 influenza is associated with a low rate of vaccination. Am J Respir Crit Care Med 2014;189:485-7.

10. Deiss RG, Arnold JC, Chen WJ, et al. Vaccine-associated reduction in symptom severity among patients with influenza A/H3N2 disease. Vaccine 2015;33:7160-7.

11. Casado I, Domínguez A, Toledo D, et al.; Project Pi12/2079 Working Group. Effect of influenza vaccination on the prognosis of hospitalized influenza patients. Expert Rev Vaccines 2016;15:425-32.

12. Loubet P, Samih-Lenzi N, Galtier F, et al.; FLUVAC Study Group. Factors associated with poor outcomes among adults hospitalized for influenza in France: a three-year prospective multicenter study. J Clin Virol 2016;79:68-73.

13. Petrie JG, Cheng C, Malosh RE, et al. Illness severity and work productivity loss among working adults with medically attended acute respiratory illnesses: US influenza vaccine effectiveness network 2012-2013. Clin Infect Dis 2016; 62:448-55.

14. Ohmit SE, Thompson MG, Petrie JG, et al. Influenza vaccine effectiveness in the 2011-2012 season: protection against each circulating virus and the effect of prior vaccination on estimates. Clin Infect Dis 2014;58:319-27.

15. Li GM, Chiu C, Wrammert J, et al. Pandemic H1N1 influenza vaccine induces a recall response in humans that favors broadly cross-reactive memory $B$ cells. Proc Natl Acad Sci U S A 2012;109:9047-52.

16. Sullivan SG, Kelly H. Stratified estimates of influenza vaccine effectiveness by prior vaccination: caution required. Clin Infect Dis 2013;57:474-6.

17. Skowronski DM, Janjua NZ, Sabaiduc S, et al. Influenza A/subtype and B/lineage effectiveness estimates for the 2011-2012 trivalent vaccine: cross-season and cross-lineage protection with unchanged vaccine. J Infect Dis 2014;210:126-37.

18. Martínez-Baz I, Casado I, Navascués A, et al. Effect of repeated vaccination with the same vaccine component against 2009 pandemic influenza $A(H 1 N 1)$ virus. $J$ Infect Dis 2017;215:847-55.

19. Ndifon W, Wingreen NS, Levin SA. Differential neutralization efficiency of hemagglutinin epitopes, antibody interference, and the design of influenza vaccines. Proc Natl Acad Sci U S A 2009;106:8701-6.

20. McLean HQ, Thompson MG, Sundaram ME, et al. Impact of repeated vaccination on vaccine effectiveness against influenza $A(H 3 N 2)$ and $B$ during 8 seasons. Clin Infect Dis 2014;59:1375-85.

21. Castilla J, Navascués A, Casado I, et al.; Primary Health Care Sentinel Network; Network for Influenza Surveillance in Hospitals of Navarre. Combined effectiveness of prior and current season influenza vaccination in northern Spain: 2016/17 mid-season analysis. Euro Surveill 2017;22:30465.

22. Skowronski DM, Chambers C, De Serres G, et al. Serial vaccination and the antigenic distance hypothesis: effects on influenza vaccine effectiveness during A(H3N2) epidemics in Canada, 2010-2011 to 2014-2015. J Infect Dis 2017; 215:1059-99.

23. Casado I, Toledo D, Soldevila N, et al. Planning and execution of a multicentre case-control study to evaluate the effectiveness of the influenza and pneumococcal vaccines in the elderly. Vacunas 2017;18:11-7.

24. Gherasim A, Martínez-Baz I, Castilla J, et al.; cycEVA working group. Effect of previous and current vaccination against influenza $A(H 1 N 1) p d m 09, A(H 3 N 2)$, and B during the post-pandemic period 2010-2016 in Spain. PLoS One 2017;12: e0179160.

25. Seasonal influenza in the EU/EEA countries, 2014-15. Stockholm: European Centre for Disease Prevention and Control (ECDC); 2015. Available: http://ecdc. europa.eu/en/publications/Publications/seasonal-influenza-risk-assessment. pdf (accessed 2017 July 28).

26. Kissling E, Nunes B, Robertson C, et al.; I-MOVE case-control study team. I-MOVE multicentre case-control study 2010/11 to 2014/15: Is there within-season waning of influenza type/subtype vaccine effectiveness with increasing time since vaccination? Euro Surveill 2016;21:30201. 
27. Thomas PG, Keating R, Hulse-Post DJ, et al. Cell-mediated protection in influenza infection. Emerg Infect Dis 2006;12:48-54.

28. Garnacho-Montero J, Gutiérrez-Pizarraya A, Màrquez JA, et al.; Spanish Society of Intensive Care Medicine and Coronary Units Working Group. Epidemiology, clinical features, and prognosis of elderly adults with severe forms of influenza A (H1N1). J Am Geriatr Soc 2013;61:350-6.

29. Skowronski DM, Hottes TS, McElhaney JE, et al. Immuno-epidemiologic correlates of pandemic H1N1 surveillance observations: higher antibody and lower cellmediated immune responses with advanced age. J Infect Dis 2011;203:158-67.
30. Ramsay LC, Buchan SA, Stirling RG, et al. The impact of repeated vaccination on influenza vaccine effectiveness: a systematic review and meta-analysis. BMC Med 2017;15:159.

31. Sullivan SG, Cowling BJ, Greenland S. Frailty and influenza vaccine effectiveness. Vaccine 2016;34:4645-6.

32. Chaves SS, Pérez A, Miller L, et al. Impact of prompt influenza antiviral treatment on extended care needs after influenza hospitalization among communitydwelling older adults. Clin Infect Dis 2015;61:1807-14.
Competing interests: Itziar Casado and Jesús Castilla received research grants from the Horizon 2020 programme of the European Commission (agreement 634446) and from the Carlos III Health Institute through the European Regional Development Fund (FEDER) (INT15/00182 and CM15/00119), during the conduct of the study. Diana Toledo and Angela Domínguez received research grants from the Catalan Agency for the Management of Grants for University Research (AGAUR Grant no. 2014/ SGR 1403) and from the Carlos III Health Institute through FEDER (PI12/02079), during the conduct of the study. No other competing interests were declared.

This article has been peer reviewed.

Affiliations: Instituto de Salud Pública de Navarra - IdiSNA (Casado, Castilla), Pamplona, Spain; Departament de Medicina (Domínguez, Toledo), Universitat de Barcelona, Barcelona, Spain; Complejo Hospitalario de Navarra (Chamorro), Pamplona, Spain; Subdirección General de Epidemiología (Astray), Madrid, Spain; Hospital de GaldakaoUsansolo (Egurrola), Vizcaya, Spain; Complejo Hospitalario Universitario de Granada (Fernández-Sierra), Granada, Spain; Instituto de Biomedicina, Universidad de León (Martín), León, Spain; Departament de Medicina Preventiva (Morales-Suárez-Varela), Universitat de Valencia, Valencia, Spain; Agència de Salut Pública de Catalunya (Godoy), Institut de Recerca Biomèdica de Lleida, Lleida, Spain; CIBER Epidemiología y Salud Pública CIBERESP (Casado, Domínguez, Toledo, Martín, Morales-Suárez-Varela, Godoy, Castilla), Madrid, Spain.

Contributors: All of the authors participated in the design, implementation and interpretation of the study. Itziar Casado conducted the statistical analyses and had full access to the study data. Itziar Casado and Jesus Castilla wrote the initial draft of the manuscript. All of the authors revised the manuscript critically for important intellectual content, gave final approval of the version to be published and agreed to be accountable for all aspects of the work.

Members of the Project PI12/02079 Working Group (by region): J.M Mayoral MD PhD, Servicio de Vigilancia de Andalucía; J. Díaz-Borrego MD, Servicio Andaluz de Salud; A. Morillo MD PhD, Hospital Universitario Virgen del Rocío; M.J. Pérez-Lozano MD PhD, Hospital Universitario Virgen de Valme; J. Gutiérrez MD, Hospital Universitario Puerta del Mar; M. Pérez-Ruiz PhD, M.A. Fernández-Sierra MD, Complejo Hospitalario Universitario de Granada, Andalusia, Spain; S. Tamames MD PhD, Dirección General de Salud Pública, Investigación, Desarrollo e Innovación, Junta de Castilla y León; S. RojoRello PhD, Hospital Clínico Universitario de Valladolid; R. Ortiz de Lejarazu MD PhD, Universidad de Valladolid; M.I. Fernández-Natal MD PhD, Complejo Asistencial Universitario de León; T. Fernández-Villa PhD, GIIGAS-Grupo de Investigación en Interacción Gen-Ambiente y Salud, Universidad de León; A. Pueyo MD, Hospital Universitario de Burgos; V. Martín PhD, Universidad de León and CIBERESP, Castile and Léon, Spain; A. Vilella MD PhD, Hospital Clínic; M. Campins MD PhD, A. Antón MSc, Hospital Universitari Vall d'Hebron, Universitat Autónoma de Barcelona; G. Navarro MD, Corporació Sanitària i Universitaria Parc Taulí; M. Riera BSc, Hospital Universitari Mútua Terrassa; E. Espejo MD, Hospital de Terrassa; M.D. Mas BSC, R. Pérez MD, ALTHAIA, Xarxa Hospitalaria de Manresa; J.A. Cayla MD PhD, C. Rius MD PhD, Agència de Salut Pública de Barcelona and CIBERESP; P. Godoy MD PhD, Agència de Salut Pública de Catalunya, Institut de Recerca Biomèdica de Lleida, Universitat de Lleida and CIBERESP; N. Torner MSc PhD, Agència de Salut Pública de Catalunya, Universitat de
Barcelona and CIBERESP; C. Izquierdo MSc PhD, R. Torra MD, Agència de Salut Pública de Catalunya; L. Force MD PhD, Hospital de Mataró; A. Domínguez MD PhD, N. Soldevila BSc, I. Crespo BSc PhD, D. Toledo BSc MPH, Universitat de Barcelona and CIBERESP, Catalonia, Spain; M. Morales-Suárez-Varela PhD, Universidad de Valencia and CIBERESP; F. Sanz MD PhD, Consorci Hospital General Universitari de Valencia, Valencia Community, Spain; J. Astray MD PhD, M.F. Domínguez-Berjon MD PhD, M.A. Gutiérrez MD, S. Jiménez MD, E. Gil MD, F. Martín MD, R. Génova-Maleras BSc, Dirección de Salud Pública; M.C. Prados MD PhD, F. Enzzine de Blas MD, M.A. Salvador MD, S. Rodríguez MD, M. Romero MD, Hospital Universitario la Paz; J.C. Galán MD, E. Navas MD, L. Rodríguez MD, Hospital Ramón y Cajal; C.J. Álvarez MD, E. Banderas MD, S. Fernández MD, Hospital Universitario 12 de Octubre, Madrid, Spain; M. Egurrola MD, M.J. López de Goicoechea BSc, Hospital de Galdakao, Basque Country, Spain; J. Chamorro MD, Complejo Hospitalario de Navarra; I. Casado MD, J. DíazGonzález MD, J. Castilla MD PhD, Instituto de Salud Pública de Navarra, Instituto de Investigación Sanitaria de Navarra and CIBERESP, Navarre, Spain.

Funding: This study was supported by the Institute of Health Carlos III Health Institute through the European Regional Development Fund (FEDER) (PI12/02079, INT15/00182 and CM15/00119), the Catalan Agency for the Management of Grants for University Research (AGAUR Grant No. 2014/ SGR 1403) and the Horizon 2020 programme of the European Commission (Agreement 634446).

Accepted: Nov. 11, 2017

Correspondence to: Jesús Castilla, jcastilc@navarra.es 